\title{
Zinc finger of the cerebellum 5 promotes colorectal cancer cell proliferation and cell cycle progression through enhanced CDK1/CDC25c signaling
}

\author{
Abuduzhayier Maimaiti ${ }^{1}$, Abulaiti Aizezi ${ }^{1}$, Jianati Anniwaer ${ }^{2}$, Ayitula $^{3}$, Buhajar Ali ${ }^{4}$, \\ Mukadas Dilixiati ${ }^{1}$
}

\author{
${ }^{1}$ Department of General Medicine, People's Hospital of Xinjiang Uyghur Autonomous \\ Region, Urumqi, Xinjiang, China \\ 2Department of Emergency, Hospital of Xinjiang Uygur Autonomous Region, Urumqi, \\ Xinjiang, China \\ ${ }^{3}$ Heart Guardianship Center, the First Affiliated Hospital of Xinjiang Medical \\ University, Urumqi, Xinjiang, China \\ ${ }^{4}$ Department of Rehabilitation Medicine, People's Hospital of Xinjiang Uyghur \\ Autonomous Region, Urumqi, Xinjiang, China
}

Submitted: 27 August 2018; Accepted: 2 February 2019;

Online publication: 11 November 2019

Arch Med Sci 2021; 17 (2): 449-461

DOI: https://doi.org/10.5114/aoms.2019.89677

Copyright () 2019 Termedia \& Banach

\section{Abstract}

Introduction: Colorectal cancer (CRC), mostly caused by external or environmental factors, is the third most common and lethal cancer worldwide. Although a large number of investigations have been carried out to reveal the evolution of $C R C$, the underlying mechanisms of $C R C$ remain unclear.

Material and methods: Expression of zinc finger of the cerebellum 5 (ZIC5) in CRC tissues and cell models was measured by qRT-PCR and IHC. Cell transfection was carried out for ZIC5 overexpression or knockdown. The MTT assay was applied to examine the capacity of glioma cell proliferation. Wound healing assay and tumor invasion assay were used to test the capacity of glioma cell migration and invasion respectively. Cell cycle analysis and western blot were used to verify the apoptosis rates of CRC cells upon ZIC5 overexpression or downregulation. A further tumor Xenograft study was used to examine the effects of ZIC5 on tumor malignancy in vivo.

Results: Cell models using HCT116 and SW620 cells were established to study the ZIC5 function upon ZIC5 overexpression of knockdown. Consistently, we discovered that ZIC5 also significantly increased in Chinese CRC patients. In addition, ZIC5 promoted CRC cell proliferation through increasing the proportion of cells maintained in the S phase. ZIC5 overexpression facilitated the capacity of CRC cell migration and invasion. Inhibition of ZIC5 mitigated such malignant effects.

Conclusions: Collectively, investigations of the ZIC5 in CRC provided a new insight into CRC diagnosis, treatment, prognosis and next-step translational therapeutic developments from bench to clinic.

Key words: colorectal cancer, zinc finger of the cerebellum 5, cell cycle, CDK1/CDC25C.

\section{Introduction}

Colorectal cancer (CRC), originating from normal colon epithelial cells, is usually caused by somatic mutations of Wnt signals [1]. Unwholesome
Corresponding author:

Abulaiti Aizezi PhD

Department of General

Medicine

Peoples Hospital of Xinjiang

Uyghur Autonomous Region

830000, Urumqi, China

Phone: 0991-960200

E-mail:

Abulaitiaizezimed@163.com 
lifestyle and several hereditary mutations are the common risk factors for CRC pathogenesis [2, 3]. More than one million people worldwide suffer from the threats of CRC every year [3]. Traditional therapeutic regimens, cytoreductive surgery plus chemotherapy or radiotherapy were applicable for CRC cure and remission [4]. In addition, quality control in surgery and oncological treatment plays a pivotal role in colon cancer therapy, suggesting that the combination of modern surgery and new cytostatic agents might contribute to improved 5-year survival rates [5]. Heterogeneous molecular mechanisms of CRC were responsible for the difficulty of subsequent treatment [6]. Recent studies have revealed that immunotherapy, as a precision treatment, provides novel insights into development of CRC potential cures [7]. Non-specific immunoregulators, such as Bacillus Calmette-Guerin (BCG) and levamisole, were initially used in CRC treatments [7]. Consequently, passive (antibodies or immune cells) and active (vaccination) specific immunotherapy was applied in CRC therapeutic strategies, showing higher efficiency compared to the traditional therapeutic regimen $[7,8]$.

Zinc finger of the cerebellum 5 (ZIC5), as a member of zinc finger of the cerebellum family, manipulated the target gene expression as a transcription factor or co-factor [9]. Genetic mutations of ZIC usually caused congenital malformations [10]. Although there was no evidence of ZIC5 mutations in humans, ZIC5 deficiency was reported to lead to neural tube defects and neural crest abnormalities in mouse models [10]. Moreover, recent studies showed that higher expression of ZIC was closely associated with cancer progression and recurrence. Mechanistically, ZIC5 can increase the expression levels of genes which may be involved in the malignant proliferation of cancer cells, such as Wnt and cyclin D1. ZIC5 also promoted $\beta$-catenin to enter the nucleus of hepatocellular carcinoma (HCC) cells [11-14]. For example, Aruga et al. reported that ZIC1/2/5 was highly expressed in meningiomas, and could be a diagnostic marker [11]. Inaguma et al. indicated that ZIC2, cooperating with Gli signaling pathways, facilitated pancreatic cancer cells' malignant proliferation [12]. Later, ZIC5 was reported to be a promising marker of Gleason score 6 prostate cancer [13]. More recently, ZIC5 showed a critical role in CRC pathogenesis [14]. However, how ZIC5 regulated CRC malignancy remains unclear. In this study, we examined for the first time the expression of ZIC5 in Chinese CRC patients and found that ZIC5 was up-regulated. In addition, in-depth studies revealed that ZIC5 promoted CRC cell proliferation and ameliorated apoptosis through CDK1/CDC25C signaling. Also, ZIC5 could prevent CRC cell migration and invasion. Flavopiridol [15], an inhibitor of CDK, inhibited the malignant effect caused by ZIC5 overexpression. Collectively, our results showed that the CDK1/CDC25C pathway was critical to ZIC5-mediated CRC progression. Drugs specifically targeted to CDKs urgently needed to be developed and provided a new insight into CRC treatment and translational investigations.

\section{Material and methods}

\section{Patients and serum samples}

This project was carried out with the permissions from patients and was approved by the ethics committee of the People's Hospital of Xinjiang Uyghur Autonomous Region University. All procedures performed in the studies involving human participants were in accordance with the 1964 Helsinki Declaration and its later amendments or comparable ethical standards. Clinical cancer tissue samples from 60 CRC patients at the People's Hospital of Xinjiang Uyghur Autonomous Region Hospital from 2016 to 2017 were collected for ZIC5 examination. Paired normal tissues were also harvested for negative control. Samples were collected with liquid nitrogen and stored at $-80^{\circ} \mathrm{C}$. All these patients received no radiotherapy or chemotherapy before surgery.

\section{Cell culture}

Human colon carcinoma cells including SW620 and HCT116 were purchased from the Bena culture collection Co., Ltd (Jiangsu, China). Cells were cultured in Dulbecco's modified Eagle's medium (DMEM) supplemented with 10\% FBS and 1\% penicillin/streptomycin (Gibco, USA). A cell incubator with a humidified atmosphere containing $5 \% \mathrm{CO}_{2}$ was applied for all cell cultures. In addition, flavopiridol $(4.5 \mathrm{mmol} / \mathrm{l})$ was prepared in water and then added into the colon cancers for functional assay.

\section{RNA extraction and real-time PCR analysis}

We used the mirVana miRNA kit (Takara, China) to extract total RNAs from CRC samples or cultured cells following the manufacturer's instructions. U6 small RNA was used as an internal control. For detection of ZIC5 mRNA expression, PrimeScript RT reagent kit (Takara, Dalian, China) was applied to synthesize the first-strand cDNA. The expression of ZIC5 was quantified by real-time PCR mixture assays (Takara). GAPDH was used as the internal control. Primers were designed as follows:

ZIC5_Forward: 5'-GCGCUGAGAUUAGCGGAUUTT-3'. ZIC5_Reverse: 5'-AAUCCGCUAAUCUCAGCGCTT-3' GAPDH_Forward: 5'-GGAGCGAGATCCCTCCAAAAT-3' GAPDH_Reverse: 5'-GGCTGTTGTCATACTTCTCATGG-3' 


\section{Cell transfection}

Cells transfection was used for ZIC5 overexpression or inhibition. In brief, we amplified the human ZIC5 CDNA through PCR and then subcloned into the pcNDA3.1 vector (Invitrogen). siZIC5 were designed as follow:

siZIC5_Forward: 5'-GCGCUGAGAUUAGCGGAUUTT -3' siZIC5_Reverse: 5'-AAUCCGCUAAUCUCAGCGCTT -3'

Lipofectamine 2000 (Invitrogen, USA) was applied to efficiently transfect ZIC5 or siZIC5 in CRC cells according to the manufacturer's instructions.

\section{MTT assay}

The MTT assay kit (Thermo Fisher, USA) was used to assess the viability of SW620 and HCT116 cells transfected with ZIC5 or siZIC5. In brief, $20 \mu \mathrm{l}$ of MTT reagent was added into each well and then these cells were incubated at $37^{\circ} \mathrm{C}$ for $4 \mathrm{~h}$. We aspirated the medium and added $100 \mu \mathrm{l}$ of DMSO to dissolve the formazan crystals. A microplate reader was used to examine the absorbance at $450 \mathrm{~nm}$.

\section{Western blot assays}

Expression levels of proliferative cell cycle proteins, such as CDC25C, CDK1, and cyclin B1, were determined by western blot. Briefly, CRC (SW620 and HCT116) cells were lysed using RIPA buffer. Primary antibodies, such as rat anti-cyclin B1 (Santa Cruz, 1 : 500), rat-anti CDC25C (Sigma, 1 : 1000) and mouse anti-CDK1 (Santa Cruz, $1: 1000)$ were incubated with PVDF membrane at room temperature for 3-4 h. Secondary antibodies conjugated with HRP were used to detect the protein expression at room temperature for $1 \mathrm{~h}$ through chemiluminescence reagent. $\beta$-actin was used as an internal reference.

\section{Cell cycle analysis}

Trypsin was applied to digest the transfected CRC cells, which were subsequently fixed in $70 \%$ ethanol. Cells were washed with $1 \times$ PBS and treated with $10 \mu \mathrm{g} / \mathrm{ml}$ RNase for $1 \mathrm{~h}$ at $37^{\circ} \mathrm{C}$, and propidium iodide $(100 \mu \mathrm{g} / \mathrm{ml})$ was used for staining at room temperature for 30 min in dark. A flow cytometer (BD Bioscience, San Jose, CA, USA) was used to analyze cell cycle distribution and the data were analyzed by FlowJo.

\section{Wound healing assay}

Wound healing assay was used to detect cell migration. Briefly, transfected cells $\left(1 \times 10^{4}\right.$ cells $/$ well) were seeded in 6-well plates, and then an artificial homogeneous wound was created via a sterile plastic micropipette tip. Next, cells were cultured under standard conditions for $24 \mathrm{~h}$. Cells were imaged from 0 to $24 \mathrm{~h}$ after wounding. Cells that migrated from the wound edge in five random fields were counted through a microscope (Olympus, Japan)

\section{Cell invasion assay}

Capacity of CRC cell invasion was evaluated by transwell chambers (BD Biosciences). In brief, $5 \times$ $10^{4}$ CRC cells were placed into the upper chamber with Matrigel (BD, USA) for $24 \mathrm{~h}$. Then 10\% FBS was added as a chemoattractant in the bottom chamber. $48 \mathrm{~h}$ after seeding, we removed the upper chamber cells via a cotton swab and fixed the bottom chamber cells with $70 \%$ ethanol for $30 \mathrm{~min}$. Finally, these cells were stained with $0.2 \%$ crystal violet for $10 \mathrm{~min}$. A microscope (Olympus, Japan) was applied to count the fixed cells of five randomly selected fields.

\section{Histology and immunohistochemistry}

A microtome was used to harvest CRC tissue sections (5 $\mu \mathrm{m}$ thickness). Sections were first put into xylene and graded alcohol for deparaffinization. Citrate buffer was used to expose the antigen by heating at $95^{\circ} \mathrm{C}$ for $15 \mathrm{~min}$. After the sections cooled down, we washed the sections with $1 \times$ PBS and then added the blocking solution to neutralize the peroxidase activity for $1 \mathrm{~h}$. Primary antibodies (ZIC5, R\&D, $1: 200$ ) were incubated with sections for $12 \mathrm{~h}$ at $4^{\circ} \mathrm{C}$ and then secondary antibodies were added for $1 \mathrm{~h}$ incubation at $37^{\circ} \mathrm{C}$. Finally, DAB solution was added for target antigen detection. Mayer's hematoxylin was used as a counter stain. In negative controls, the primary antibodies were omitted.

\section{Tumor xenograft study}

Four-week-old male immune deficiency nude mice were purchased from Beijing Vital River Laboratory Animal Technology Co. Ltd. Animal experiments were approved by the People's Hospital of Xinjiang Uyghur Autonomous Region University. $2 \times 10^{6}$ SW620 cells were transfected with ZIC5. These cells were then suspended in sterile saline $(0.2 \mathrm{ml})$ and subcutaneously injected into the axillary fossae of each nude mouse. After implantation of cancer cells, mice were killed at different time points (1w, 2w, 3w, 4w, 5w, 6w) and consequently xenograft tumors were harvested intact. Fresh tissues were stored in liquid nitrogen for next-step RNA and/or protein extraction.

\section{Data analysis}

Data are presented as mean \pm standard deviation. Statistical analyses between two groups were performed using Student's t-test via SPSS 
16.0. Statistical analyses between multiple groups were performed using one-way analysis of variance (ANOVA) followed by the least significant difference post-hoc test. Differences with values of $p<0.05$ were regarded as statistically significant.

\section{Ethical approval}

The study was approved by the Animal Ethics Committee of the People's Hospital of Xinjiang Uyghur Autonomous Region, and the experiments with rats were in full compliance with the European Communities Council Directive of 24 November $1986(86 / 609 / E E C)$ or with the Guidelines laid down by the NIH in the US.

\section{Results}

Zinc finger of the cerebellum 5 was up-regulated in CRC patients

To examine the role of ZIC5 in CRC, samples derived from 60 patients were collected to examine the expression levels of ZIC5. Consistently, we found that ZIC5 was significantly increased compared to paired normal tissues (Figures $1 \mathrm{~A}, \mathrm{~B}$ ). We further assessed the correlation between ZIC5 and clinicopathological parameters; 60 CRC patients were chosen to examine the effect on ZIC5 in CRC prognosis. As shown in Table I, higher expression of ZIC5 was observed in highly malignant primary tumors $(T 2 / 3)(p=0.026)$. As for lymph node metastasis, higher expression of ZIC5 in CRC patients was prior to occur $(p=0.004)$. In addition, CRC patients with higher ZIC5 expression showed a significant increase in CRC distal metastasis $(p=0.002)$. However, there were no significant relations observed in ZIC5 and other clinicopathological parameters.

\section{CDK1/CDC25A signaling \\ cascade-mediated ZIC5 induced malignant CRC cell proliferation}

To assess the functional role of ZIC5 in CRC, two CRC cell lines (SW620 and HCT116) were used to elevate or knock down the expression of ZIC5.

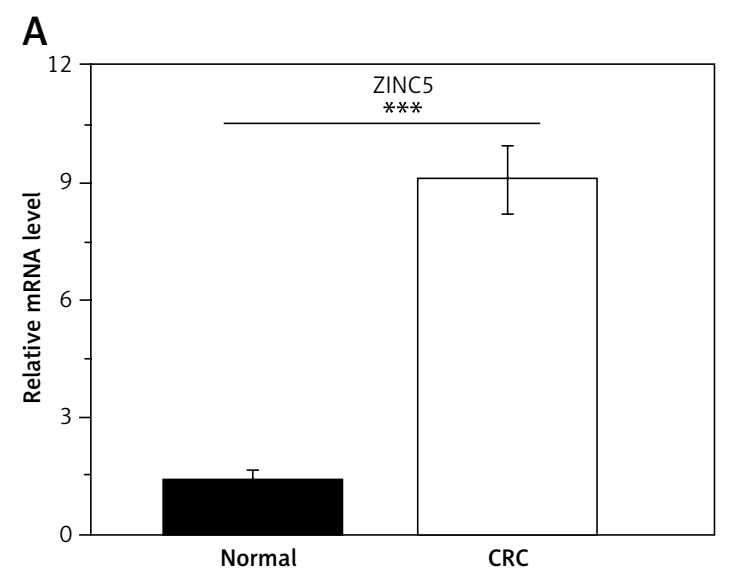

B
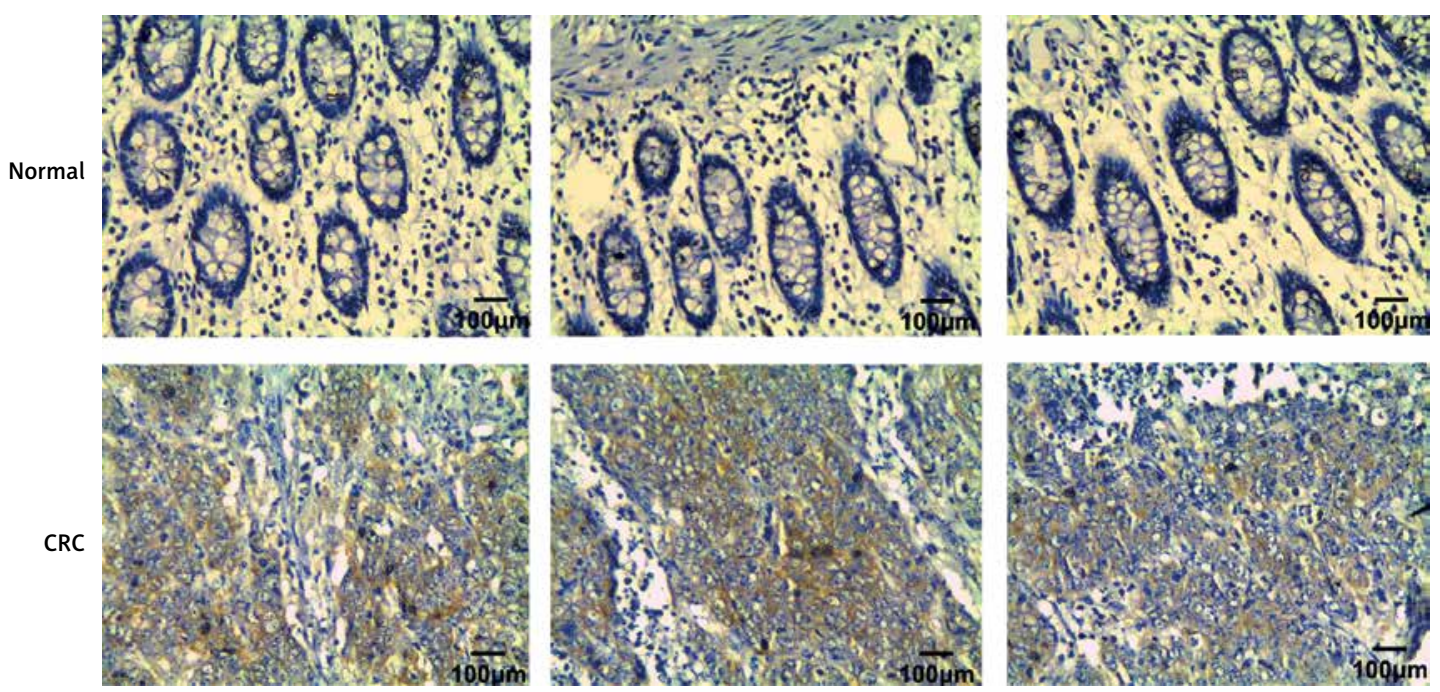

Figure 1. Zinc finger of the cerebellum 5 expression was significantly increased in CRC tissue samples. A - qRT-PCR results revealed that expression of ZIC5 in CRC patients was significantly higher than that in paired normal tissues. B - ZIC5 expression was elevated in CRC patients compared with paired normal tissues $\left(n=3\right.$ patients; ${ }^{* * *} p<$ 0.001 ; scale bar $=100 \mu \mathrm{m})$ 
The efficiency of ZIC5 expression was examined by qRT-PCR and Western blot (Figures 2 A, B). The capacity of cell proliferation showed an increased tendency in a time-dependent manner (Figure $2 \mathrm{C}$ ) upon ZIC5 overexpression in SW620 cells, whereas the proliferation of HCT116 cells was down-regulated (Figure 2 D) under ZIC5 knockdown. Next, cell cycle analysis showed a higher proportion of SW620 cells maintained in the S phase upon ZIC5 overexpression, illustrating a higher proliferation rate (Figure $2 \mathrm{E}$ ). In contrast, a large amount of HCT116 cells stayed at G0/G1 phase in the condition of ZIC5 deficiency, demonstrating that inhibition of ZIC5 could induce CRC cell cycle arrest at G0/G1 phase. As we know, CDC25/CDK/cyclin signaling was essential for cell cycle regulation, so we further investigated whether the CDC25/ CDK/cyclin pathway was activated. As expected, the expression levels of CDC25C, CDK1 and cyclin $\mathrm{B} 1$ were all elevated. Considering the major role of $\mathrm{CDC} 25 \mathrm{C}$ in the nucleus during mitosis, nuclear proteins from CRC cells were further extracted to verify the CDC25C function (Figures $2 \mathrm{~F}, \mathrm{G}$ ) upon ZIC5 overexpression of knockdown. CDC25c expression was significantly increased in the nucleus but not in the cytoplasm. Oppositely, ZIC5 deficiency caused lower expression of nuclear CDC25c. Taken together, the results obtained from this section showed that ZIC5 played a pivotal role in CRC proliferation.

\section{Zinc finger of the cerebellum 5 promoted CRC cell migration and invasion}

The CRC patients, treated with surgery and several adjuvant therapies, usually suffered from relapse and metastasis. As shown in Table I, ZIC5 was closely associated with the metastasis of CRC. We subsequently investigate the role of ZIC5 in CRC cell migration and invasion. We found that ZIC5 overexpression accelerated the CRC cell migration and invasion. In HCT116, we knocked down the expression of ZIC5 and found that ZIC5 deficiency restricted cells' capacity for invasion and migration (Figures $3 \mathrm{~A}, \mathrm{~B}$ ), suggesting that ZIC5 had a versatile role in CRC.

\section{CDK/CDC25c signaling in CRC was positively regulated by ZIC5}

To further confirm the causal relationship between ZIC5 and CDK/CDC25c signaling, we next performed a rescue experiment in CRC cells. ZIC5 was initially overexpressed in HCT116 cells, and then malignancy was examined. We found that CRC cell proliferation, migration and invasion abilities were all elevated (Figures 4 A, C, D). Accordingly, the expression of cyclin B1, CDK1 and CDC25c was also increased (Figure 4 B). Next, the
Table I. Physical examination data of IC patients and correlation analysis with zinc finger of the cerebellum 5 (ZIC5) expression level

\begin{tabular}{|c|c|c|c|}
\hline Parameter & $\begin{array}{l}\text { Low level } \\
\text { of ZIC5 } \\
\text { expression } \\
\text { number } \\
(n=30)\end{array}$ & $\begin{array}{l}\text { High level } \\
\text { of ZIC5 } \\
\text { expression } \\
\text { number } \\
(n=30)\end{array}$ & $P$-value \\
\hline Age [years]: & & & 0.195 \\
\hline$>60$ & 17 & 11 & \\
\hline$\leq 60$ & 13 & 19 & \\
\hline Gender: & & & 0.121 \\
\hline Male & 15 & 16 & \\
\hline Female & 15 & 14 & \\
\hline Primary tumor: & & & $0.026^{*}$ \\
\hline $\mathrm{T} 1$ & 16 & 6 & \\
\hline $\mathrm{T} 2$ & 12 & 19 & \\
\hline T3 & 2 & 5 & \\
\hline $\begin{array}{l}\text { Lymph node } \\
\text { metastasis: }\end{array}$ & & & $0.004^{* *}$ \\
\hline NO & 20 & 9 & \\
\hline $\mathrm{N} 1-2$ & 10 & 21 & \\
\hline $\begin{array}{l}\text { Distal } \\
\text { metastasis: }\end{array}$ & & & $0.002^{\star \star}$ \\
\hline MO & 22 & 10 & \\
\hline M1 & 8 & 20 & \\
\hline TNM stage: & & & $0.002^{* *}$ \\
\hline I & 12 & 4 & \\
\hline II & 9 & 3 & \\
\hline III & 6 & 11 & \\
\hline IV & 3 & 12 & \\
\hline
\end{tabular}

Significant correlation: ${ }^{*} p<0.05,{ }^{* *} p<0.01$

effect of flavopiridol (an inhibitor of CDK) on CRC cell proliferation, migration and invasion was examined. As shown in Figure 4, flavopiridol restricted CRC cell proliferation, migration and invasion abilities. Intriguingly, ZIC5-mediated effects of pro-tumor were all reversed (Figures 4 A-D) under flavopiridol treatment, suggesting that CDK/ CDC25C signaling may be regulated by ZIC5.

\section{Zinc finger of the cerebellum 5 promoted tumor formation in vivo}

Given the important role of ZIC5 in CRC, we next investigated whether ZIC5 facilitated tumor formation in vivo. SW620 cells that transiently overexpressed ZIC5 were subcutaneously injected into the axillary fossae of nude mice. The results 

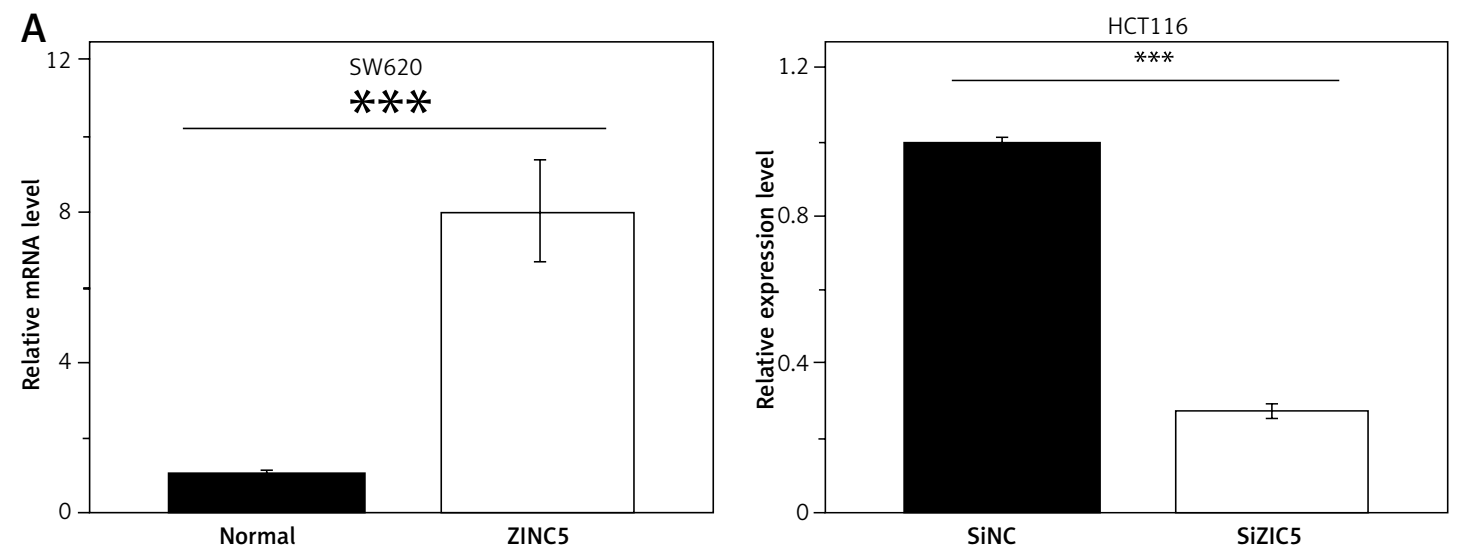

B

Normal SW620 ZINC5

ZINC5

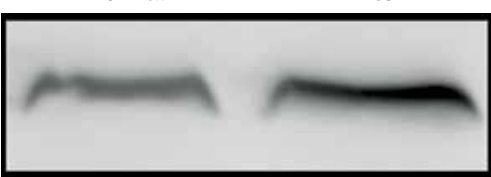

$\beta$-actin
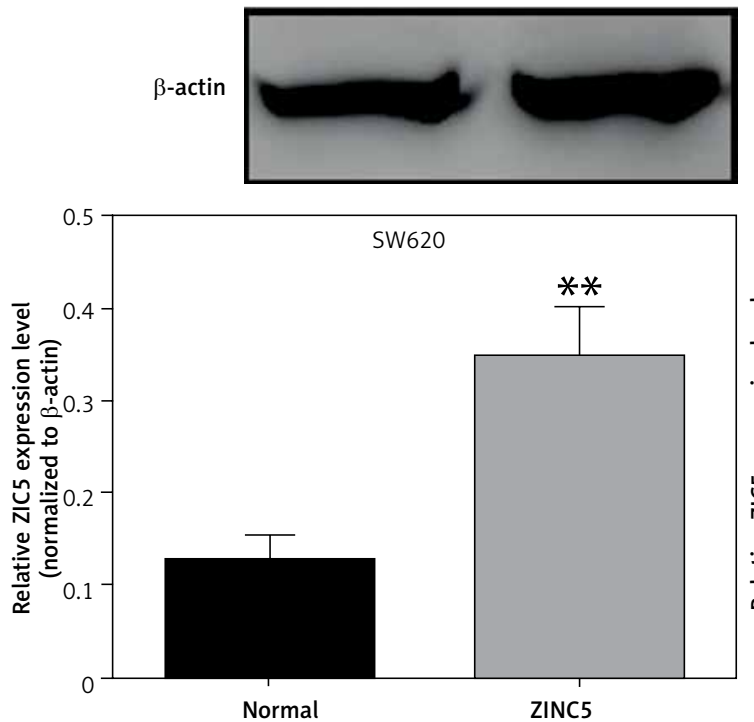

C

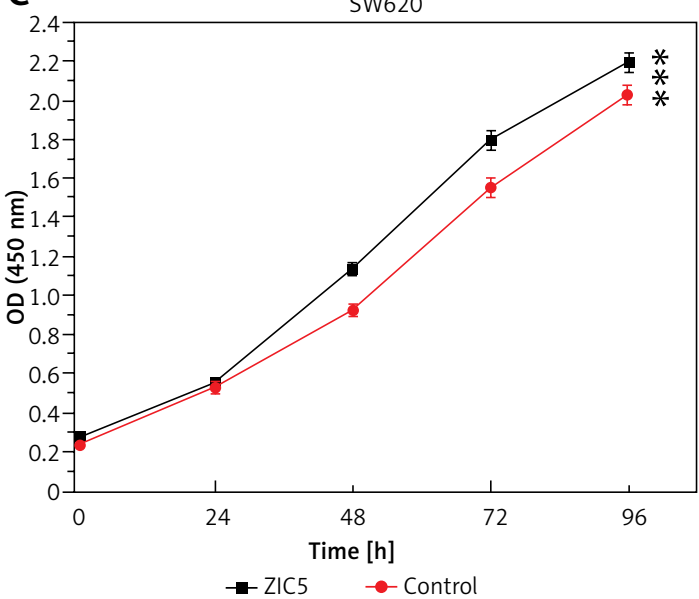

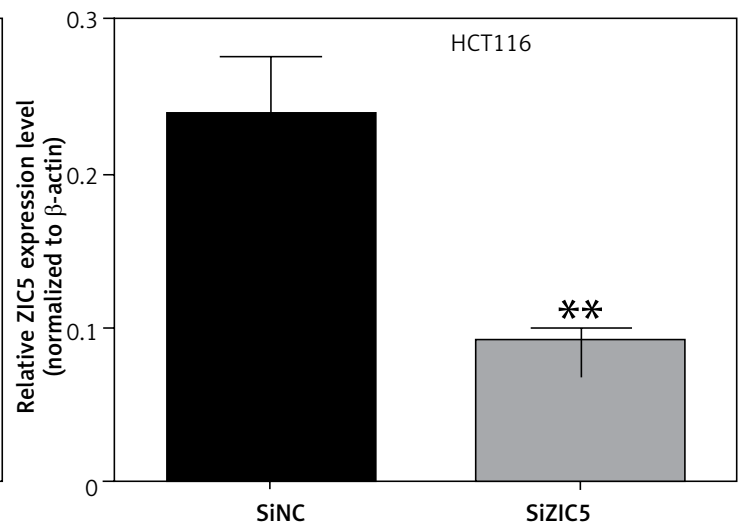

D

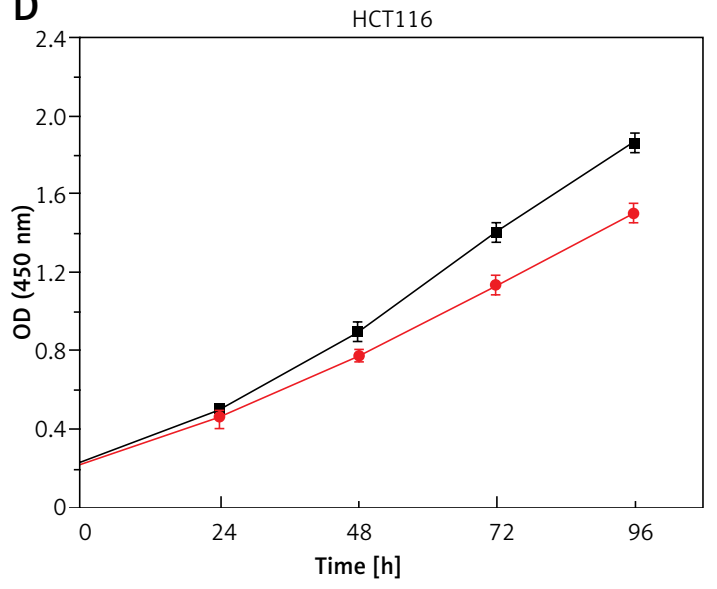

$\rightarrow$ SiNC $\rightarrow$ SiZIC5

Figure 2. Overexpression of ZIC5 promoted CRC cell proliferation through activating CDC25/CDK1/cyclin B1 signaling. SW620 cells and HCT116 cells were transfected with ZIC5 plasmid and siZIC5 respectively. A - Transfection efficiency was examined by qRT-PCR and western blot (B). C - MTT assay showed that SW620 cells transfected with ZIC5 plasmid had higher proliferation capacity, D - whereas inhibition of ZIC5 decreased HCT116 cell proliferation 

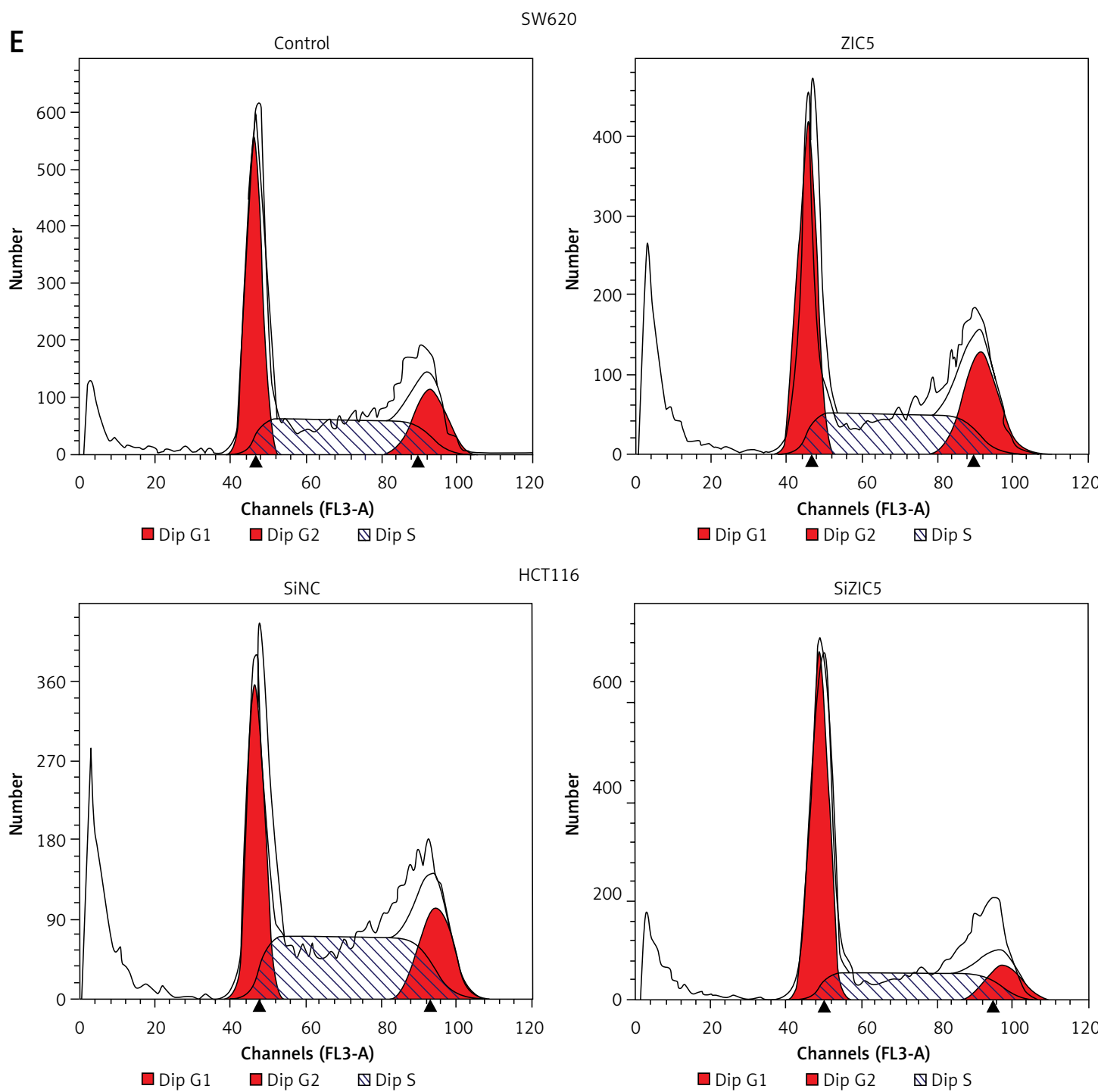

HCT116
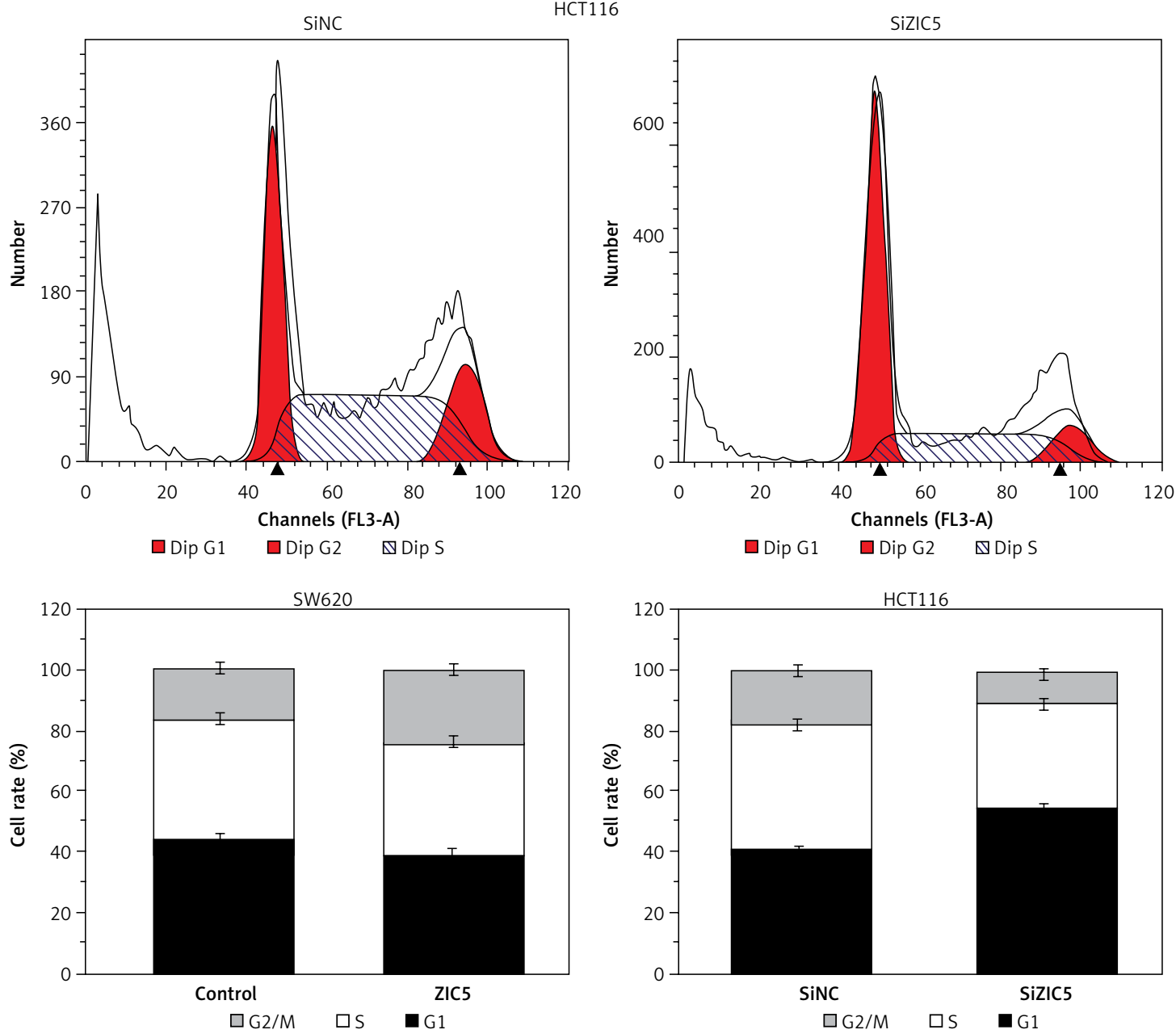

Figure 2. Cont. E - Cell cycle analysis revealed that in SW620 cells with overexpression of ZIC5, a larger proportion of cells remained in the S phase, whereas in HCT116 cells with ZIC5 knockdown, G0/G1 phase cells were increased 

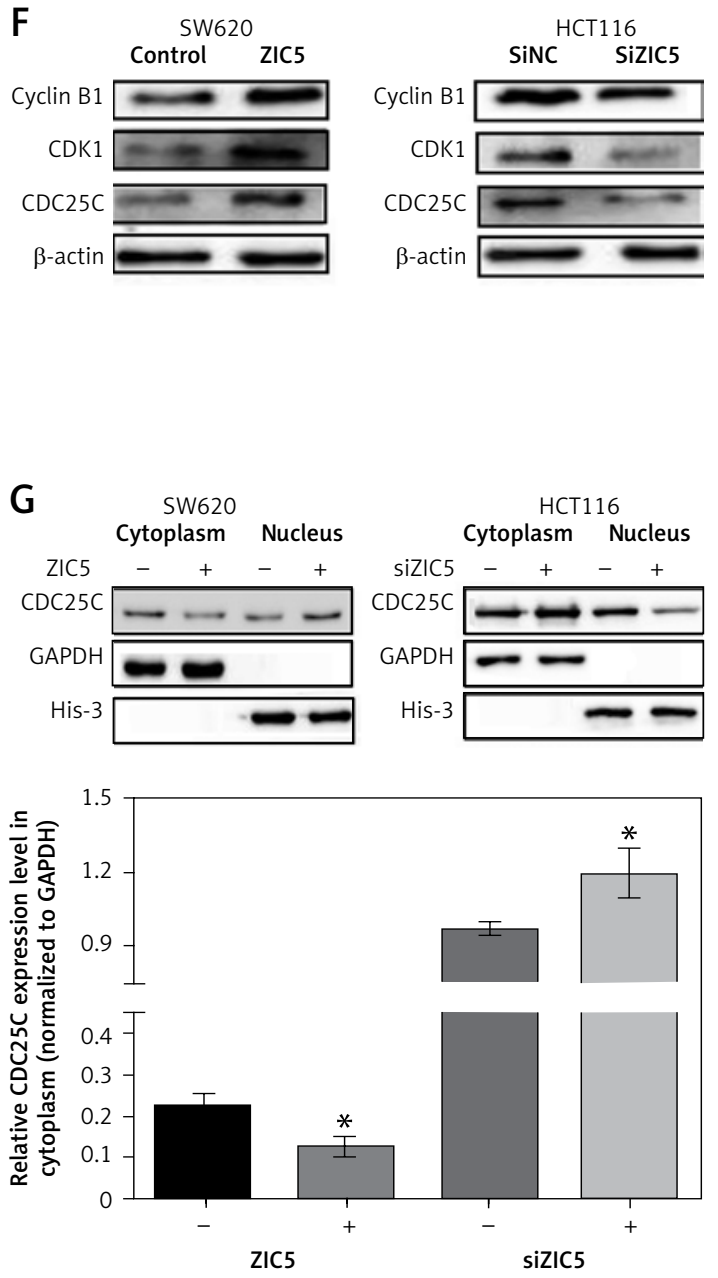
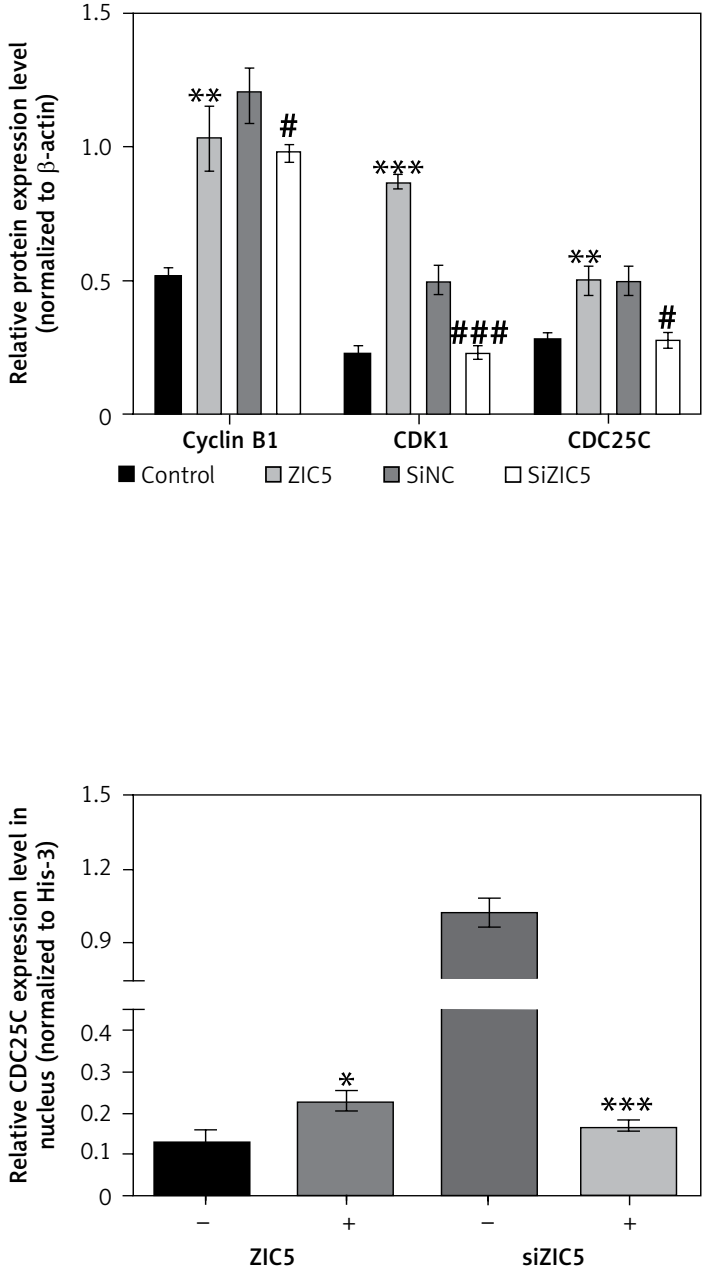

Figure 2. Cont. F, G - Western blot results showed that expression of cell cycle related proteins was up-regulated and CDC25C was translocated into the nucleus and was responsible for activation of downstream cascades $\left({ }^{* * *} p<0.001\right)$

showed that nude mice injected with ZIC5 overexpressing cells showed larger tumor formation compared with the control group, i.e., tumors volume was significantly increased (Figures 5 A, B).

\section{Discussion}

Colorectal cancer is a devastating disease in creasing mortality rate. It is extremely urgent to identify diagnostic markers for early detection and late stage therapy. Peluso et al. reported that there were three types biomarkers for CRC [16]. Microsatellite instability (MSI), insulin-like growth factor binding protein 2 (IGFBP2), telomerase and pyruvate kinase $M 2$ were used for early CRC detection [16-18]. KRAS and BRAS mutations may indicated higher risk of CRC [19-21]. Additionally, APC, P53, EGFR and VEGF were valuable for CRC prognosis [22-24]. Recent studies revealed that ZIC5 was a novel diagnostic marker of CRC [14]. However, ZIC5 function in CRC remained unclear. In this study, we focused on the role of ZIC5 in CRC cell proliferation, migration and invasion owing to reinforced invasiveness and metastasis of CRC.
The zinc finger of the cerebellum gene family originated from Drosophila odd-paired (OPA), which is a homolog of ZIC. The human vertebrate ZIC was first characterized and named in 1996. To date, 5 types of ZICs have been identified, named ZIC1, ZIC2, ZIC3, ZIC4 and ZIC5. Subtypes of ZICS were reported to play distinct roles in organism development [25], and were also reported to be closely associated with cancers. ZIC1 expression was shown to be increased in gastric cancers [26], and ZIC1 methylation was considered as a more promising biomarker of cervical cancers, head and neck squamous cell carcinomas and breast cancers [27-29]. Furthermore, Lu et al. demonstrated that ZIC2 promoted hepatocellular tumor growth and metastasis [30]. ZIC3 was found to be involved in lung cancer and ZIC4 methylation was also closely associated with pTa-bladder cancers [31, 32]. Interestingly, previous studies have shown that ZIC5 was a survival factor of CRC, whereas the functional role of ZIC5 in CRC remained unclear. Satow et al. speculated that ZIC5 enhanced melanoma cell proliferation, survival and drug resistance [33]. 
A

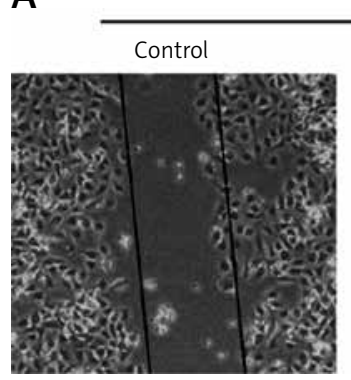

SW620

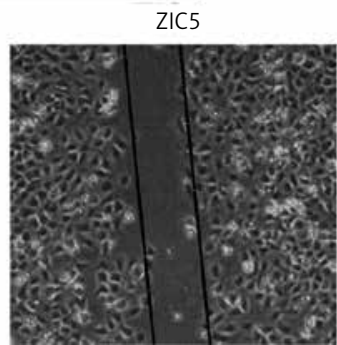

HCT116
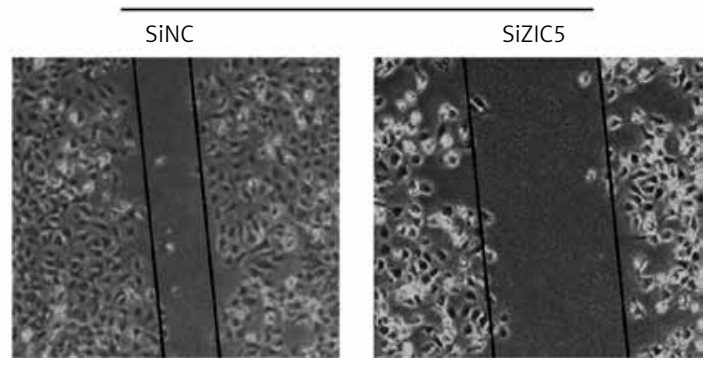

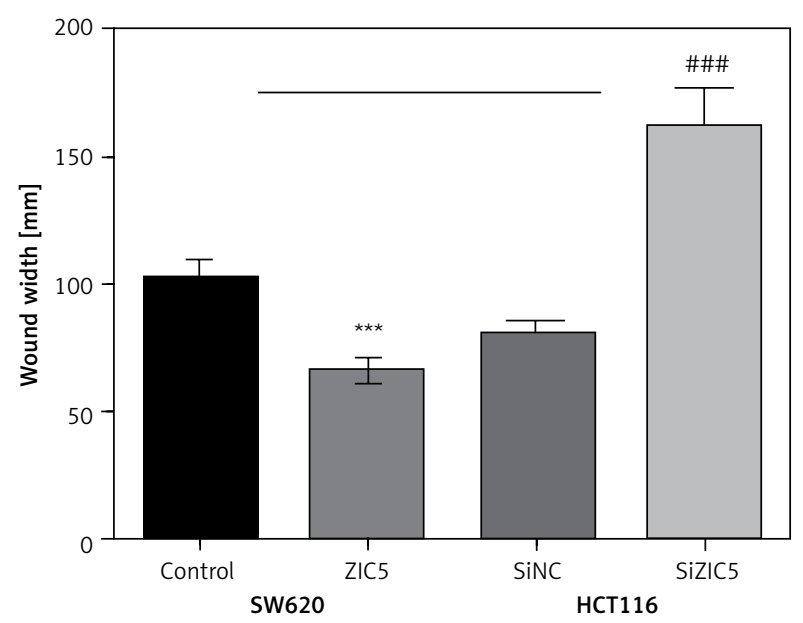

B

SW620

HCT116
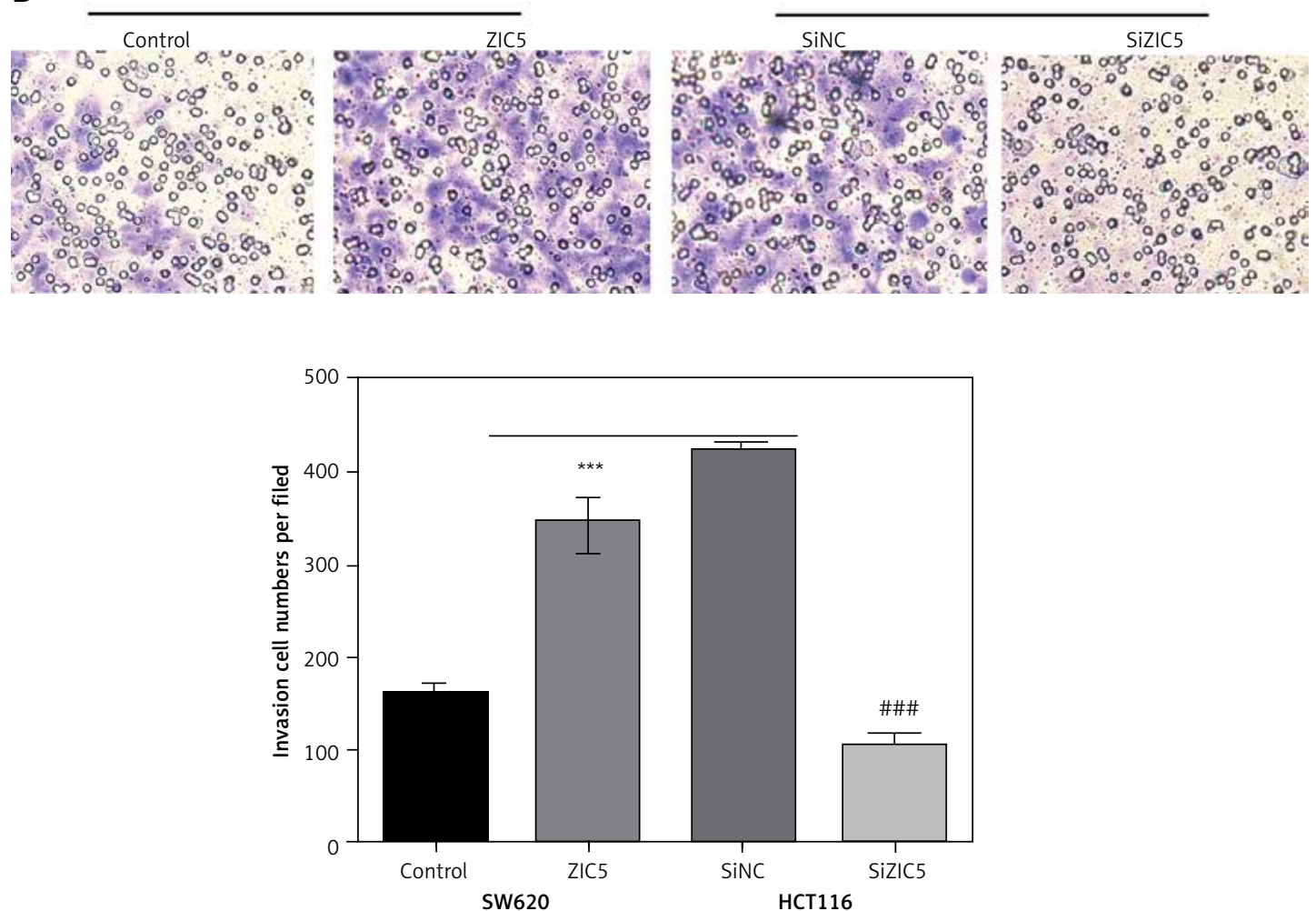

Figure 3. Zinc finger of the cerebellum 5 facilitated CRC cell migration and invasion. A - Wound healing test showed that ZIC5 promoted SW620 cell migration and inhibition of ZIC5 ameliorated HCT116 cell migration. B - ZIC5 promoted SW620 cell invasion and inhibition of ZIC5 prevented the invasion of HCT116 cells 

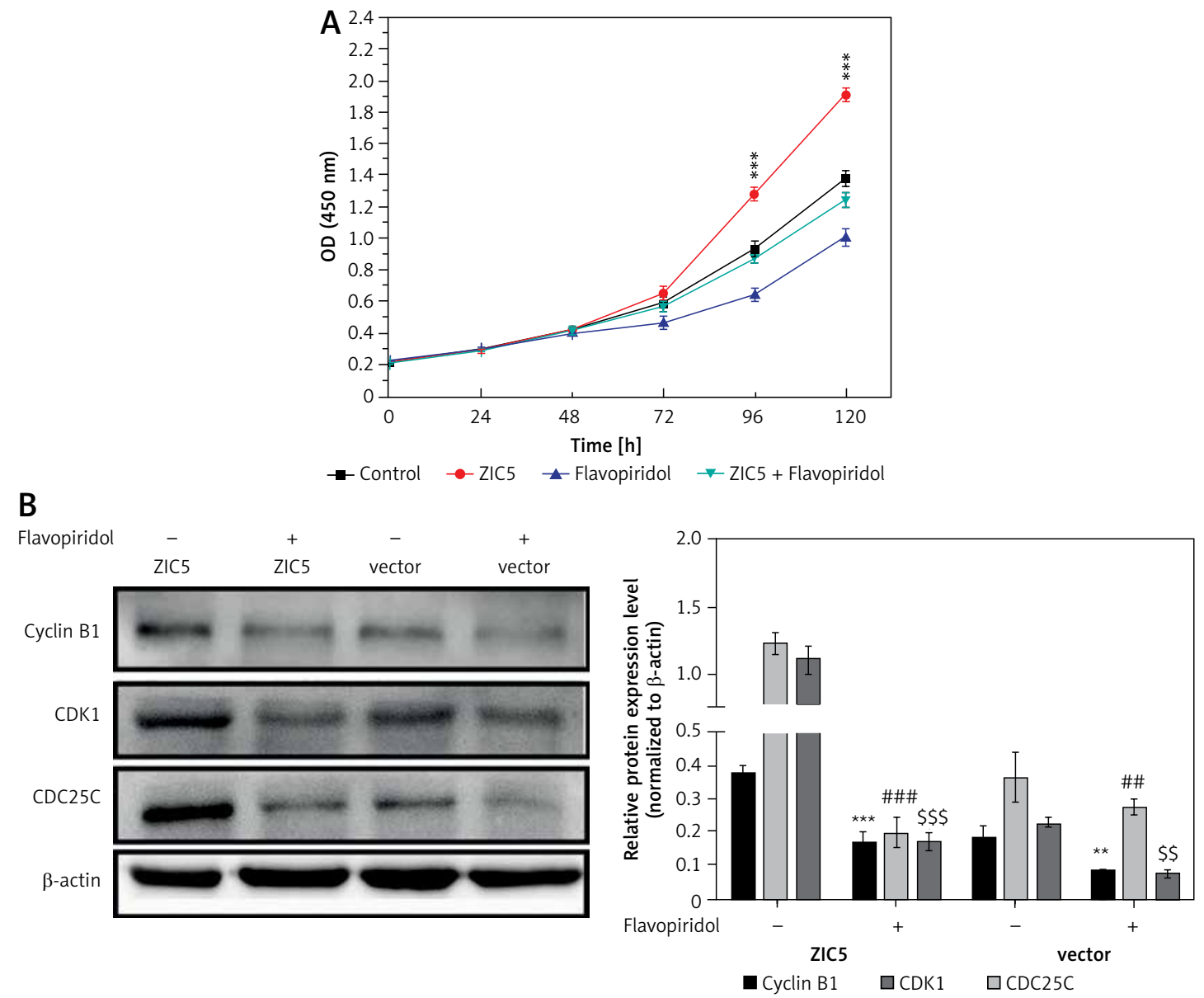

C
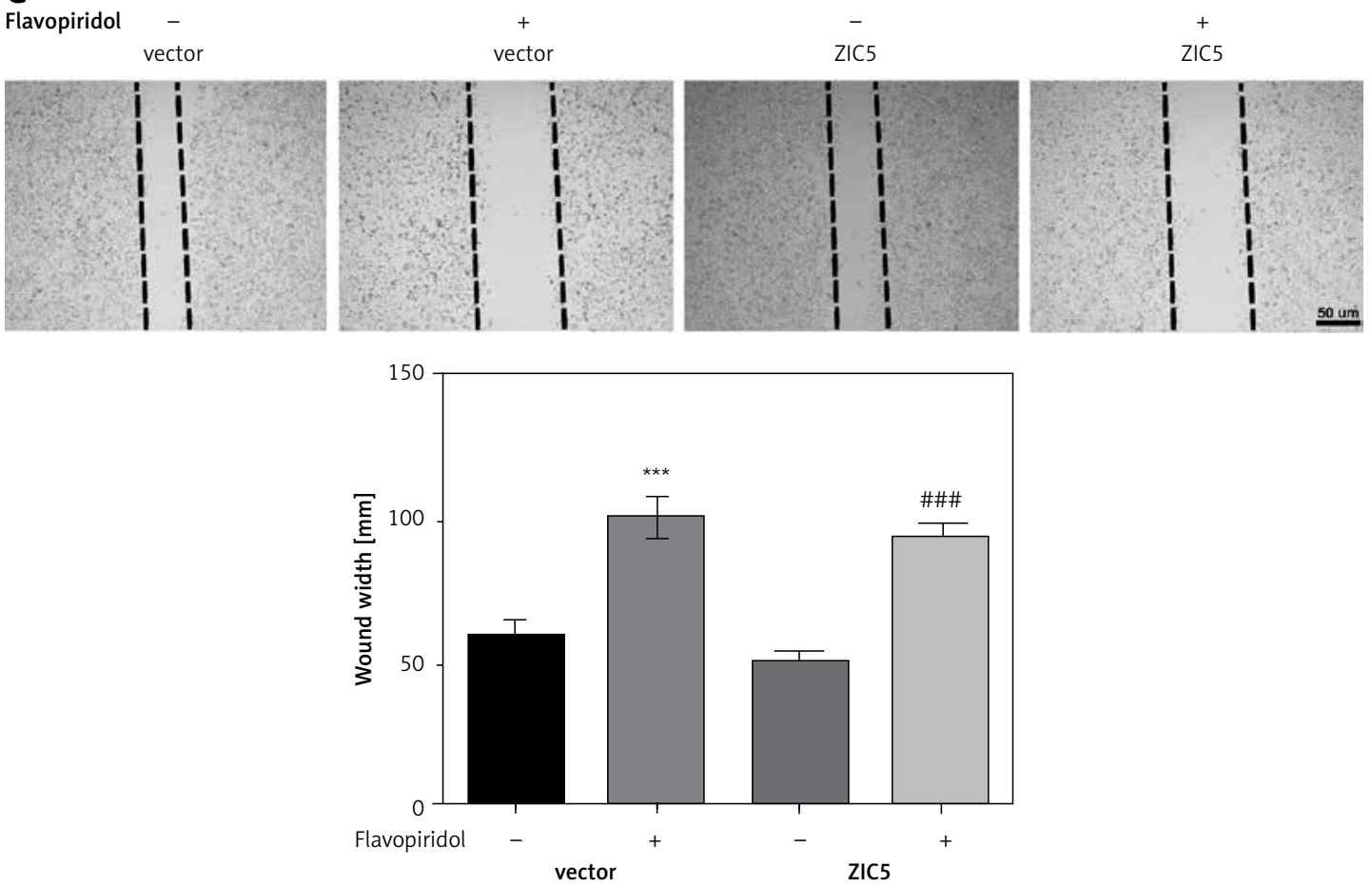

Figure 4. Flavopiridol mitigated the CRC malignancy induced by ZIC5. A - MTT assay indicated that flavopiridol restricted CRC cell proliferation induced by ZIC5 overexpression. B - Western blot results also showed the inhibitory effect of ZIC5 on the CDC25C/CDK1/cyclin B1 signaling pathway. C - Scratch assay revealed that flavopiridol inhibited CRC cell migration 
D

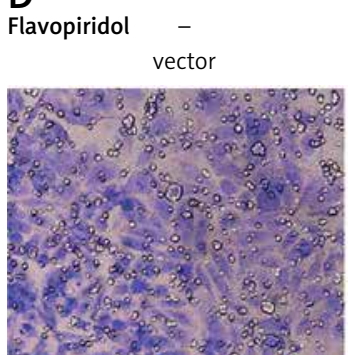

vector

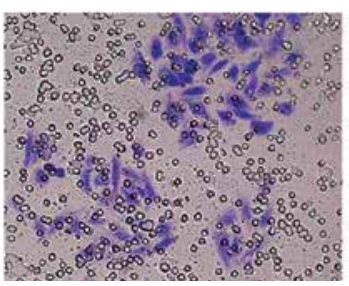

ZIC5
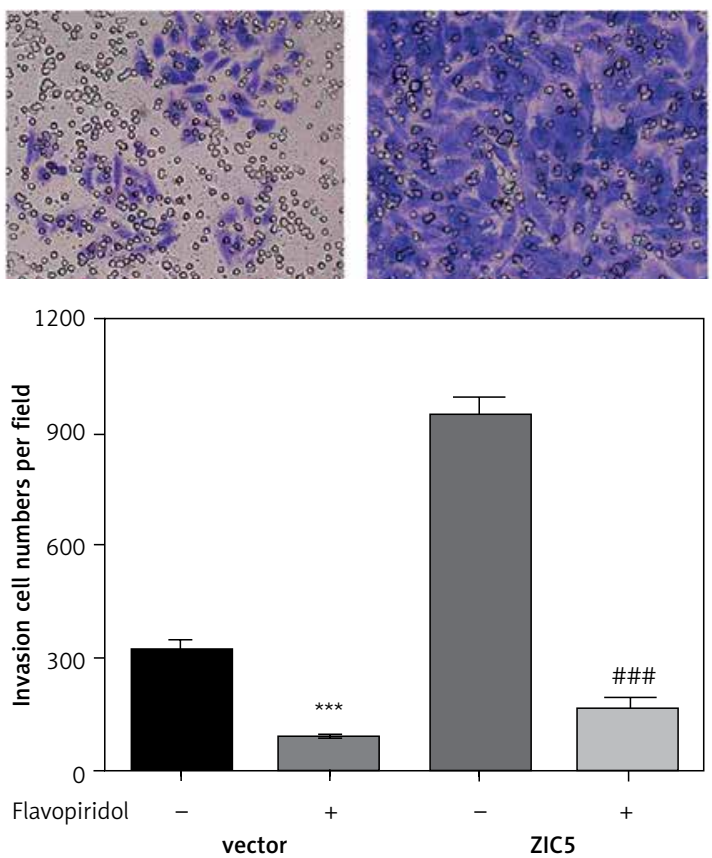

$+$

ZIC5

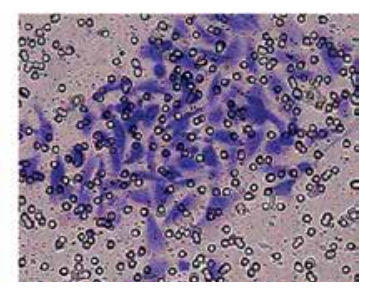

Figure 4. Cont. D - Flavopiridol inhibited ZIC5-overexpressing CRC cell invasion $\left(^{* \star *} p<0.001\right)$

\section{A}
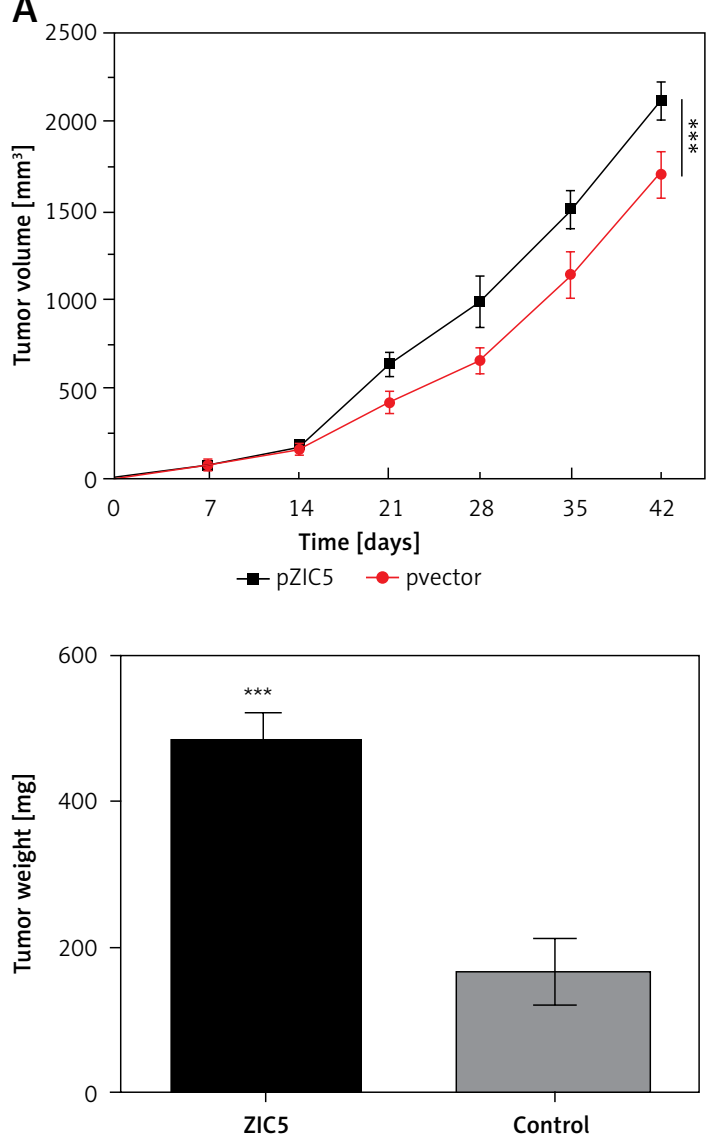

B

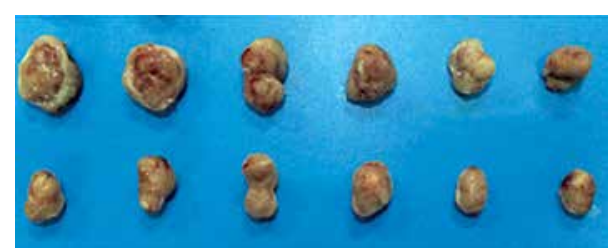

Figure 5. Zinc finger of the cerebellum 5 promoted tumor growth in vivo. A - Following the subcutaneous injection of SW620 cells with ZIC5 overexpression, tumor volume was progressively increased in a time-dependent manner. B - Morphologic phenotype of tumor from nude mice with/without ZIC-overexpressing CRC cell injection $\left({ }^{* * *} p<0.001\right)$ 
In addition, Sun et al. demonstrated that ZIC5 promoted non-small lung cancer cell proliferation [34]. Therefore, we investigated whether ZIC5 affected CRC cell proliferation, migration and invasion. Our studies showed that ZIC5 overexpressing SW620 cells had higher proliferation, migration and invasion abilities. Knockdown of ZIC5 ameliorated CRC malignancy in HCT116 cells. Consistent with other groups' findings, ZIC5 showed positive effects on colon cancer cell proliferation. Interestingly, ZIC5 also promoted colon cancer cell invasion, indicating that ZIC5 overexpression may contribute to colon cancer metastasis. But how did ZIC5 affect colon cancer cell proliferation? We hypothesized that the CRC cell cycle was altered upon ZIC5 overexpression or knockdown. Therefore, expression of cell cycle-related proteins, such as cell division cycle protein 25 (CDC25), cyclin dependent kinase 1 (CDK1) and cyclin B1, were examined. We found that expression levels of all the proteins mentioned above were elevated. Mechanistically, CDC25 could remove the phosphate from the CDK, thus activating CDK. Cyclin B, as a downstream effector of CDK, controls the cell cycle transitions from $G 1$ to $S$ phase and $G 2$ to $M$ phase [35]. The $\mathrm{CDC} / \mathrm{CDK} /$ cyclin signal pathway has shown strong linkage to human cancers [36]. Accumulating data revealed that aberrant up-regulation of $\mathrm{CDC/CDK/}$ cyclin was closely associated with clinical tumor stages, survival rate and prognosis. For example, CDK2, cyclin D1, and cyclin E and B were reported to be involved in glioblastoma [37], CRC [38] and ovarian cancers [39]. CDK signals also play an important role in HCCs through regulating Wht or NF- $\kappa B$ signaling [15].

Given the important role of $\mathrm{CDC} / \mathrm{CDK} /$ cyclin signals in cancers, we further tested the efficacy of CDK inhibitors in CRC. A common CDK inhibitor named flavopiridol that was initially used to treat leukemia [40] has been used in the treatment of arthritis and atherosclerotic plaque formation [41]. Scientists and clinicians hypothesized that interruption of the cell cycle could arrest cancer cell growth due to one of the hallmarks of cancers. Most researchers intended to gain similar therapeutic efficiency in solid tumors. Murphy et al. stated that CDK4/6 inhibitors showed promising effects on breast cancer patients [42]. Okada et al. demonstrated that flavopiridol promoted epidermoid cancer cells' and colorectal cancer cells' autophagic cell death [43]. Therefore, we tested the inhibitory effects of flavopiridol on CRC cell proliferation, migration and invasion abilities. We found that flavopiridol not only inhibited CRC malignancy but also ameliorated CRC cell proliferation, migration and invasion upon ZIC5 overexpression. Similarly, when CDK function was inhibited by flavopiridol, ZIC5-me- diated tumor promotion ability was restored, pointing out the causality between ZIC5 and CDK signaling, that is, CDK signaling may act downstream of ZIC5. Finally, we investigated whether CRC cells transiently overexpressing ZIC5 could form a tumor in vivo. Together, these results further demonstrated the important role of ZIC5 and CDK signaling in CRC progression and metastasis.

In conclusion, accumulating studies have suggested that: 1) ZIC5 manipulated colon cancer cell proliferation, migration and invasion; 2) the hyper-activated CD14/CDC25 signaling pathway is responsible for ZIC5-induced malignant proliferation of colon cancer cells; 3) ZIC5 functions as an upstream regulator of CDK signaling. In this study, we reported for the first time the effects of ZIC5 on CRC and identified a potential diagnostic marker for CRC progression, thus providing novel insights into CRC pathophysiology for future drug development, translational research and therapeutic treatment from bench to clinic.

\section{Conflict of interest}

The authors declare no conflict of interest.

\section{References}

1. Strum W. Colorectal adenomas. N Engl J Med 2016; 375: 389-90.

2. Fagunwa I, Loughrey M, Coleman H. Alcohol, smoking and the risk of premalignant and malignant colorectal neoplasms. Best Pract Res Clin Gastroenterol 2017; 31: 561-8.

3. Van Zutphen M, Kampman E, Giovannucci E, van Duijnhoven F. Lifestyle after colorectal cancer diagnosis in relation to survival and recurrence: a review of the literature. Curr Colorectal Cancer Rep 2017; 13: 370-401.

4. Ahmed S, Eng C. Role of chemotherapy in the neoadjuvant/adjuvant setting for patients with rectal adenocarcinoma undergoing chemoradiotherapy and surgery or radiotherapy and surgery. Curr Oncol Rep 2018; 20: 3.

5. Pramateftakis MG, Kanellos D, Vrakas G et al. Progress in rectal cancer staging and treatment. Tech Coloproctol 2010; 14 Suppl 1: S29-31.

6. Inamura K. Colorectal cancers: an update on their molecular pathology. Cancers (Basel) 2018; 10. pii: E26.

7. Midgley R, Kerr D. Immunotherapy for colorectal cancer: a challenge to clinical trial design. Lancet Oncol 2000; 1: 159-68.

8. Lamami Y, Mesediyeva R, Arıkan S, et al. Preliminary report: one of the PD-1 gene variants may be a valuable marker for colorectal cancer. Arch Med Sci Civil Dis 2018; 3: e34-e40

9. Ali R, Bellchambers $H$, Arkell R. Zinc fingers of the cerebellum (Zic): transcription factors and co-factors. Int J Biochem Cell Biol 2012; 44: 2065-8.

10. Grinberg I, Millen K. The ZIC gene family in development and disease. Clin Genet 2005; 67: 290-6.

11. Aruga J, Nozaki Y, Hatayama M, Odaka Y, Yokota N. Expression of ZIC family genes in meningiomas and other brain tumors. BMC Cancer 2010; 10: 79. 
12. Inaguma S, Ito H, Riku M, Ikeda H, Kasai K. Addiction of pancreatic cancer cells to zinc-finger transcription factor ZIC2. Oncotarget 2015; 6: 28257-68.

13. Hoogland AM, Bottcher R, Verhoef E, Jenster G, van Leenders GJ. Gene-expression analysis of gleason grade 3 tumor glands embedded in low- and high-risk prostate cancer. Oncotarget 2016; 7: 37846-56.

14. Satow R, Inagaki S, Kato C, Shimozawa M, Fukami K. Identification of zinc finger protein of the cerebellum 5 as a survival factor of prostate and colorectal cancer cells. Cancer Sci 2017; 108: 2405-12.

15. Park S, Jwa E, Shin S, et al. Ibulocydine sensitizes human hepatocellular carcinoma cells to TRAIL-induced apoptosis via calpain-mediated Bax cleavage. Int J Biochem Cell Biol 2017; 83: 47-55.

16. Peluso G, Incollingo P, Calogero A, et al. Current tissue molecular markers in colorectal cancer: a literature review. Biomed Res Int 2017; 2017: 2605628.

17. Boland C. Decoding hereditary colorectal cancer. N Engl J Med 2006; 354: 2815-7.

18. Piñol-Felis C, Fernández-Marcelo T, Viñas-Salas J, Valls Bautista C. Telomeres and telomerase in the clinical management of colorectal cancer. Clin Transl Onco 2017; 19: 399-408.

19. Hathurusinghe $H$, Goonetilleke K, Siriwardena A. Current status of tumor $\mathrm{M} 2$ pyruvate kinase (tumor $\mathrm{M} 2-\mathrm{PK}$ ) as a biomarker of gastrointestinal malignancy. Ann Surg Oncol 2007: 14: 2714-20.

20. Karapetis C, Khambata-Ford S, Jonker D, et al. K-ras mutations and benefit from cetuximab in advanced colorectal cancer. N Engl J Med 2008; 359: 1757-65.

21. Toon C, Chou A, DeSilva K, et al. BRAFV600E immunohistochemistry in conjunction with mismatch repair status predicts survival in patients with colorectal cancer. Mod Pathol 2014; 27: 644-50.

22. Chen T, Chang S, Huang C, et al. The prognostic significance of APC gene mutation and miR-21 expression in advanced-stage colorectal cancer. Colorectal Dis 2013; 15: 1367-74.

23. Hamelin R, Laurent-Puig P, Olschwang S, et al. Association of p53 mutations with short survival in colorectal cancer. Gastroenterology 1994; 106: 42-8.

24. Falchook G, Kurzrock R. VEGF and dual-EGFR inhibition in colorectal cancer. Cell Cycle 2015; 14: 1129-30.

25. Houtmeyers R, Souopgui J, Tejpar S, Arkell R. The ZIC gene family encodes multi-functional proteins essential for patterning and morphogenesis. Cell Mol Life Sci 2013; 70: 3791-811.

26. Ma G, Dai W, Sang A, Yang X, Li Q. Roles of ZIC family genes in human gastric cancer. Int J Mol Med 2016; 38: 259-66

27. Verlaat W, Snijders P, Novianti P, et al. Genome-wide DNA methylation profiling reveals methylation markers associated with $3 \mathrm{q}$ gain for detection of cervical precancer and cancer. Clin Cancer Res 2017; 23: 3813-22.

28. Nakakido M, Tamura K, Chung S, et al. Phosphatidylinositol glycan anchor biosynthesis, class $X$ containing complex promotes cancer cell proliferation through suppression of EHD2 and ZIC1, putative tumor suppressors. Int J Oncol 2016; 49: 868-76.

29. Paluszczak J, Wiśniewska D, Kostrzewska-Poczekaj M, et al. Prognostic significance of the methylation of Wnt pathway antagonists-CXXC4, DACT2, and the inhibitors of sonic hedgehog signaling-ZIC1, ZIC4, and HHIP in head and neck squamous cell carcinomas. Clin Oral In vestig 2017; 21: 1777-88.
30. Lu S, Zhang C, Luo R, et al. Zic2 promotes tumor growth and metastasis via PAK4 in hepatocellular carcinoma. Cancer Lett 2017; 402: 71-80.

31. Yang B, Jia L, Guo Q, et al. MiR-564 functions as a tumor suppressor in human lung cancer by targeting ZIC3. Biochem Biophys Res Commun 2015; 467: 690-6.

32. Beukers W, Kandimalla R, Masius R, et al. Stratification based on methylation of TBX2 and TBX3 into three molecular grades predicts progression in patients with pTa-bladder cancer. Mod Pathol 2015; 28: 515-22.

33. Satow R, Nakamura T, Kato C, et al. ZIC5 drives melanoma aggressiveness by PDGFD-mediated activation of FAK and STAT3. Cancer Res 2017; 77: 366-77.

34. Sun Q, Shi R, Wang X, Li D, Wu H, Ren B. Overexpression of ZIC5 promotes proliferation in non-small cell lung cancer. Biochem Biophys Res Commun 2016; 479: 502-9.

35. Dedobbeleer M, Willems E, Freeman S, Lombard A, Goffart N, Rogister B. Phosphatases and solid tumors: focus on glioblastoma initiation, progression and recurrences. Biochem J 2017; 474: 2903-24.

36. Mok M, Zhou J, Tang W, et al. CCRK is a novel signalling hub exploitable in cancer immunotherapy. Pharmacol Ther 2018; 186: 138-51.

37. Bo L, Wei B, Li C, Wang Z, Gao Z, Miao Z. Identification of potential key genes associated with glioblastoma based on the gene expression profile. Oncol Lett 2017; 14: 2045-52.

38. Zhang P, Kawakami H, Liu W, et al. Targeting CDK1 and MEK/ERK overcomes apoptotic resistance in braf mutated human colorectal cancer. Mol Cancer Res 2017; 16: 378-89.

39. Zhou Q. Targeting cyclin-dependent kinases in ovarian cancer. Cancer Invest 2017; 35: 367-76.

40. Bogenberger J, Whatcott C, Hansen N, et al. Combined venetoclax and alvocidib in acute myeloid leukemia. Oncotarget 2017; 8: 107206-22.

41. Sekine C, Sugihara T, Miyake S, et al. Successful treatment of animal models of rheumatoid arthritis with small-molecule cyclin-dependent kinase inhibitors. J Immunol 2008; 180: 1954-61.

42. Murphy $C$, Dickler $M$. The role of CDK4/6 inhibition in breast cancer. Oncologist 2015; 20: 483-90.

43. Okada Y, Kato S, Sakamoto Y, Oishi T, Ishioka C. Synthetic lethal interaction of CDK inhibition and autophagy inhibition in human solid cancer cell lines. Oncol Rep 2017; 38: 31-42. 